\title{
Early Menarche is a Risk Factor for Short Stature in Young Korean Females: An Epidemiologic Study
}

\author{
(D) Sol Kang, (D) Yoon Mo Kim, (D) Jun Ah Lee, (D) Dong Ho Kim, (D) Jung Sub Lim \\ Korea Cancer Center Hospital, Department of Pediatrics, Seoul, Republic of Korea
}

\section{What is already known on this topic?}

In European countries, age at menarche was positively associated with final adult height and negatively associated with body mass index.

\section{What this study adds?}

This is the first study to show that early menarche is a risk factor for short adult stature in Korean females. The odds ratio for short stature in females with early menarche was 2.62 after adjusting for mother's height.

\section{Abstract}

Objective: To assess the association between age at menarche and adult height [and body mass index (BMI)] in young Korean females and also to investigate whether early menarche ( $<12$ years) is a risk factor for short stature and obesity in young Korean females.

Methods: Data on 1148 females aged 18-30 years and 612 mother (612 pairs of mothers and daughters) from the 6th Korea National Health and Nutrition Examination Survey (2013-2015) were analyzed.

Results: Among 1148 females, 256 (22.3\%) had early menarche. Their stature was approximately $0.445 \mathrm{~cm}$ shorter when menarche had occurred one year earlier. The prevalence of short stature $(\leq 153 \mathrm{~cm})$ and obesity (BMI $\geq 25)$ was higher in females with early menarche compared to those with later menarche (short stature: $10.5 \%$ vs $6.4 \%$, obesity; $20.7 \%$ vs $13.1 \%$, all p < 0.001 ). In multivariate regression, the odds ratio (OR) for short stature was 2.62 [95\% confidence interval (CI): 1.26-5.44] after adjusting for current age and mother's height. OR for obesity was 1.74 (95\% CI: 0.98-3.07) after adjusting for age and maternal BMI.

Conclusion: Final height in girls is influenced by age of menarche. Early menarche increased the risk for adult short stature in young Korean females.

Keywords: Early menarche, short stature, adult height, obesity, KNHANES

\section{Introduction}

Age of menarche is known to be influenced by several factors, such as genetics, ethnicity, geography, socioeconomic status and especially nutritional status $(1,2,3,4)$. Several studies including this one have reported a relationship between early menarche age ( $<12$ years) and the risk of obesity, insulin resistance, metabolic syndrome, nonalcoholic fatty liver disease, diabetes and cardiovascular disease in adulthood $(5,6,7,8,9)$. Thus, management of risk factors for early menarche in the pediatric population may reduce the risk of adult metabolic disease.
Short stature is typically defined as an adult height that is more than two standard deviations (SD) below the mean for age and sex (10). In developed countries, this typically includes adult men who are shorter than $166 \mathrm{~cm}$ and adult women who are shorter than $153 \mathrm{~cm}$. Several factors might cause short adult height. The main factors appear to be the effects of multiple familial genes and environment, and the complex interplay between these. In addition, short adult height can be caused by pathological states, including genetic disease such as Turner syndrome, prolonged chronic disease, malnutrition, prolonged treatment with certain drugs (steroids) and hormone deficiency states such 
as growth hormone deficiency. Short adult height may also occur because of early fusion of growth plates as a result of precocious puberty (11).

In Europe and the USA, women with earlier menarche were reported to have reached shorter adult height compared to women who had menarche at a later age $(12,13,14)$. Furthermore, in Asian countries including Korea, female age of menarche has recently shown a downward trend to younger age $(5,15,16)$.

The aim of this study was to investigate whether final adult height is associated with age at menarche in young Korean females. We also assessed whether an independent association exists between early menarche and short adult stature or obesity in Korean females. For this purpose, we investigated the data of 12,537 women who participated in the Korea National Health and Nutrition Examination Survey (KNHANES-VI).

\section{Methods}

The data of the $6^{\text {th }}$ KNHANES-VI (2013-2015) data were used in the study. KNHANES-VI is a cross-sectional survey with multi-staged, stratified sampling design and offers nationally representative data conducted by the Division of Chronic Disease Surveillance, Korea Centers for Disease Control and Prevention (17). Written informed consent was secured by all of the participants before the study had begun, and the KNHANES was conducted following ethical approval by the Institutional Review Board of the Korea Centre for Disease Control and Prevention (No: 2013-07CON-03-4C, 2013-12EXP-03-5C).

Among the 12,537 females who participated in KNHANES-VI, we selected data on menarcheal age and anthropometric variables. There were 1148 young females aged 18 to 30 years and mothers' height and weight data were available in 612 of the 1148 subjects. Weight was determined to the nearest $0.1 \mathrm{~kg}$ on a medical balance (GL-6000-20, CAS, Seoul, Korea) and height was measured to the nearest $0.1 \mathrm{~cm}$ with a wall-mounted stadiometer (Seca 220, Seca, Hamburg, Germany). Body mass index (BMI) was calculated by dividing the weight by the height squared $\left(\mathrm{kg} / \mathrm{m}^{2}\right)$. Height in Korean females reaches a near plateau at age 16 according to 2017 Korean National Growth Charts (18).

"Age of menarche" is defined as age of the first menstrual period and the data was collected using the questionnaire method. The question was open-ended: "At what age did you have your first menstrual period (menarche)?" Age of years represents age between 11.00-11.99 years. We defined early menarche as $<12$ years. Short stature was defined as a height less than $\leq 153 \mathrm{~cm}$ ( $\leq 5^{\text {th }}$ percentile of a female Korean population) and obesity as a BMI $\geq 25$, using Asian criteria (19). Household income as a surrogate marker of socioeconomic status was assessed according to the following categorical variables: low (1Q), lower middle (2Q), upper middle $(3 \mathrm{Q})$, and high $(4 \mathrm{Q})$ in KNHANES.

\section{Statistical Analysis}

Data related to anthropometric measurements and other covariates were stratified by early menarche and later menarche. The Student's t-test and chi-square test were used in the comparison of early menarche and later menarche. Continuous variables are reported as means $\pm \mathrm{SD}$, and categorical variables are reported as percentages (\%). Linear regression analysis was used to evaluate the predictors of the subject's height as a dependent variable using heights at menarche as predictive variables, controlling for current age. For the assessment of odds ratios (ORs) of short stature or obesity according to early menarche, multivariable logistic regression was used. The ORs including $95 \%$ confidence interval $(\mathrm{CI})$, between early menarche and short stature (or obesity) were calculated before and after adjusting for age, and other confounders. In the final analysis, household income was excluded as there was no significant difference of prevalence of short stature from quartile to quartile. All statistical analyses were performed by using SPSS 17.0 for Windows (SPSS Inc., Chicago, IL, USA). P values < 0.05 were considered significant.

\section{Results}

The characteristics of the study subjects were divided according to early menarche or later menarche and are summarized in Table 1. At the time of the study, the mean \pm SD current age of all subjects was $23.5 \pm 3.5$ years. Mean \pm SD age of menarche was $12.7 \pm 1.6$ years. Mean \pm SD (range) height was $161.6 \pm 5.8(138-179) \mathrm{cm}$ and mean $\pm \mathrm{SD}$ (range) BMI was $21.6 \pm 3.7(15-49) \mathrm{kg} / \mathrm{m}^{2}$.

Among the 1148 female subjects, 256 (22.3\%) had early menarche and 892 had later menarche. Mean \pm SD current age was significantly younger in the early menarche group $(22.9 \pm 3.4$ vs $23.7 \pm 3.5$ years; $p=0.001)$. This group was also significantly shorter $(160.4 \pm 5.1$ vs $161.9 \pm 6.0 \mathrm{~cm}$; $\mathrm{p}<0.001)$ and had a higher BMI (22.4 \pm 3.8 vs $21.3 \pm 3.5$; $\mathrm{p}<0.001$ ) than the later menarche group, The early menarche group also had a higher prevalence of short stature (10.5\% vs $6.4 \%)$ and obesity ( $20.7 \%$ vs $13.1 \%$ ) (see Figure 1). However, there was no difference in prevalence affected by household income. 
In the subgroup of subjects with available maternal anthropometric data $(n=612)$, the mean \pm SD age of the mothers was $50.3 \pm 4.6$ years and maternal mean \pm SD age at menarche was $14.3 \pm 1.7$ years. Differences in age, age at menarche, height and BMI between mother and daughter were $27.5 \pm 3.5$ years, $1.5 \pm 2.0(-4$ to 8$)$ years, $4.4 \pm 5.9(-20$ to 23$) \mathrm{cm}$ and $2.5 \pm 3.9 \mathrm{~kg} / \mathrm{m}^{2}$, respectively.

There was no difference in mother's age, height, weight and BMI values between the early menarche and later menarche groups. However, the mothers of subjects with early menarche had earlier menarche than mothers of subjects with later menarche $(13.8 \pm 1.5$ vs $14.4 \pm 1.7$ years; $\mathrm{p}<0.001)$. There was also no difference in prevalence of short stature and obesity in the mothers.

Table 1. Characteristics of the subjects stratified by age at menarche

\begin{tabular}{|c|c|c|c|}
\hline \multirow[b]{2}{*}{ Characteristics } & \multicolumn{3}{|c|}{ Age at menarche } \\
\hline & $\begin{array}{l}\text { Early } \\
\text { menarche } \\
(<12 \\
\text { years })\end{array}$ & $\begin{array}{l}\text { Later } \\
\text { menarche } \\
(\geq 12 \text { years })\end{array}$ & $\mathrm{p}$ value \\
\hline \multicolumn{4}{|l|}{ Subjects } \\
\hline Number & 256 & 892 & \\
\hline Age of menarche (years) & $10.7 \pm 0.6$ & $13.2 \pm 1.2$ & $<0.001$ \\
\hline $\begin{array}{l}\text { Age at time of survey } \\
\text { (years) }\end{array}$ & $22.9 \pm 3.4$ & $23.7 \pm 3.5$ & 0.001 \\
\hline Height (cm) & $160.4 \pm 5.1$ & $161.9 \pm 6.0$ & $<0.001$ \\
\hline Weight (kg) & $57.6 \pm 10.5$ & $56.0 \pm 9.9$ & 0.026 \\
\hline Body mass index $\left(\mathrm{kg} / \mathrm{m}^{2}\right)$ & $22.4 \pm 3.8$ & $21.3 \pm 3.5$ & $<0.001$ \\
\hline \multicolumn{4}{|l|}{ Household income } \\
\hline Low $(1 Q)$ & $0.9 \%$ & $8.7 \%$ & $\begin{array}{l}0.077 \\
\text { (for all } \\
\text { SES) }\end{array}$ \\
\hline Lower middle (2Q) & $22.6 \%$ & $28.3 \%$ & \\
\hline Upper middle (3Q) & $29.9 \%$ & $32.0 \%$ & \\
\hline High (4Q) & $38.9 \%$ & $30.9 \%$ & \\
\hline \multicolumn{4}{|l|}{ Mothers } \\
\hline Number & 131 & 481 & \\
\hline Age of menarche (years) & $13.8 \pm 1.5$ & $14.4 \pm 1.7$ & $<0.001$ \\
\hline $\begin{array}{l}\text { Age at time of survey } \\
\text { (years) }\end{array}$ & $50.0 \pm 3.4$ & $50.3 \pm 3.5$ & 0.479 \\
\hline Height (cm) & $157.6 \pm 4.4$ & $157.6 \pm 5.5$ & 0.933 \\
\hline Weight (kg) & $58.6 \pm 7.2$ & $58.6 \pm 8.2$ & 0.968 \\
\hline Body mass index $\left(\mathrm{kg} / \mathrm{m}^{2}\right)$ & $23.6 \pm 2.7$ & $23.6 \pm 3.2$ & 0.921 \\
\hline $\begin{array}{l}\text { Daughter-mother height } \\
\text { difference }(\mathrm{cm})\end{array}$ & $3.3 \pm 5.3$ & $4.7 \pm 6.0$ & 0.009 \\
\hline \multicolumn{4}{|c|}{$\begin{array}{l}\text { Differences between subjects with early menarche }(<12 \text { years) and later } \\
\text { menarche ( } \geq 12 \text { years) were compared using Student's t-test for continuous } \\
\text { variables and chi-square test for } \% \text {. }\end{array}$} \\
\hline SES: socioeconomic status & & & \\
\hline
\end{tabular}

Height and BMI according to age at menarche are depicted in Figure 2. In linear regression, female grew approximately $0.445 \mathrm{~cm}$ shorter when menarche occurred one year earlier calculated as: subject's height $(\mathrm{cm})=$ subject's age at menarche (years) x 0.445 - subject's age (years) $\mathrm{x}$ $0.03+156.56\left(R^{2}=0.014 ; p<0.001\right)$. The ORs for short stature and obesity in females with early menarche compared to later menarche are summarized in Table 2. The crude OR for short stature in a female with early menarche

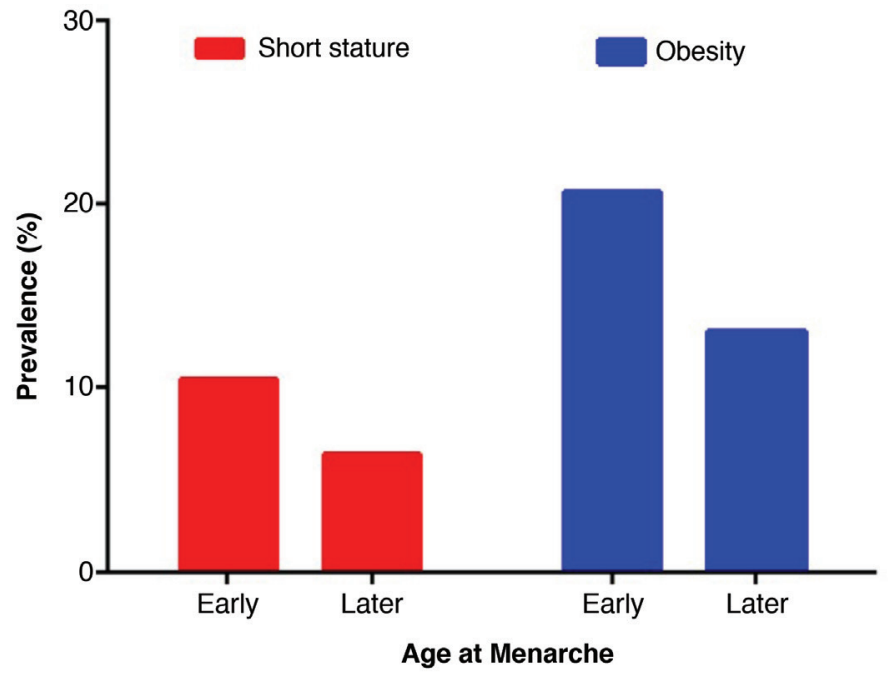

Figure 1. Prevalence of short stature and obesity according to early and later menarche. Females with early menarche had higher prevalence of short stature (10.5 vs 6.4\%) and obesity (20.7 vs $13.1 \%$ )

Table 2. Odds ratios for short stature and obesity between subjects with early menarche and the reference group

\begin{tabular}{|c|c|c|c|}
\hline & \multicolumn{2}{|c|}{$\begin{array}{l}\text { Early } \\
\text { menarche } \\
(<12 \text { years })\end{array}$} & \multirow[t]{2}{*}{$\begin{array}{l}\text { Later } \\
\text { menarche } \\
(\geq 12 \text { years })\end{array}$} \\
\hline & OR & $95 \% \mathrm{CI}$ & \\
\hline Short stature* & 1.73 & $1.07-2.79$ & 1.00 \\
\hline Model 1 age & 1.71 & $1.06-2.78$ & 1.00 \\
\hline $\begin{array}{l}\text { Model } 2 \text { age }+ \text { mother's } \\
\text { height }\end{array}$ & 2.62 & $1.26-5.44$ & 1.00 \\
\hline Obesity $\neq$ & 1.73 & $1.21-2.45$ & 1.00 \\
\hline Model 1 age & 1.79 & $1.25-2.58$ & 1.00 \\
\hline $\begin{array}{l}\text { Model } 2 \text { age }+ \text { mother's } \\
\text { BMI }\end{array}$ & 1.74 & $0.98-3.07$ & 1.00 \\
\hline \multicolumn{4}{|c|}{$\begin{array}{l}\text { *Short stature is defined as below the } 5^{\text {th }} \text { percentile of Korean females aged } \\
20-30 \text { (16) }\end{array}$} \\
\hline \multicolumn{4}{|c|}{$\neq$ Obesity was defined as $\mathrm{BMI} \geq 25 \mathrm{~kg} / \mathrm{m}^{2}$} \\
\hline \multicolumn{4}{|c|}{$\begin{array}{l}\text { * Odds ratios of short stature and obesity of early menarche compared with } \\
\text { later menarche, multivariate logistic regression was used. }\end{array}$} \\
\hline \multicolumn{4}{|c|}{$\begin{array}{l}\text { BMI: body mass index, CI: confidence interval, OR: odds ratio, Model 1: } \\
\text { Results were adjusted for current age (in years), Model 2: Results were } \\
\text { adjusted for age (in years), mother's height (or BMI) }\end{array}$} \\
\hline
\end{tabular}


was 1.73. The OR decreased to 1.71 after adjusting for current age (Model 1) and increased to 2.62 after further adjusting for mother's height (Model 2). Here, the $\operatorname{Exp}(\mathrm{B})$ of mother's height was 0.799 (95\% CI: 0.742-0.860). The OR for obesity in females with early menarche was 1.73 . The OR increased to 1.79 after adjusting for current age (Model 1) and subsequently decreased to 1.74 (95\% CI: 0.98-3.07) after adjusting for age and mother' BMI (Model 2).

\section{Discussion}

In this study, we found that for each year earlier that menarche occurred in young Korean females final height was $0.445 \mathrm{~cm}$ less. We also found that females with early menarche had a $10.5 \%$ chance of having short adult stature, the rate of which was 2.62-fold higher than those with later menarche. In addition, the OR for obesity in females with early menarche was 1.73 compared to those with later menarche.
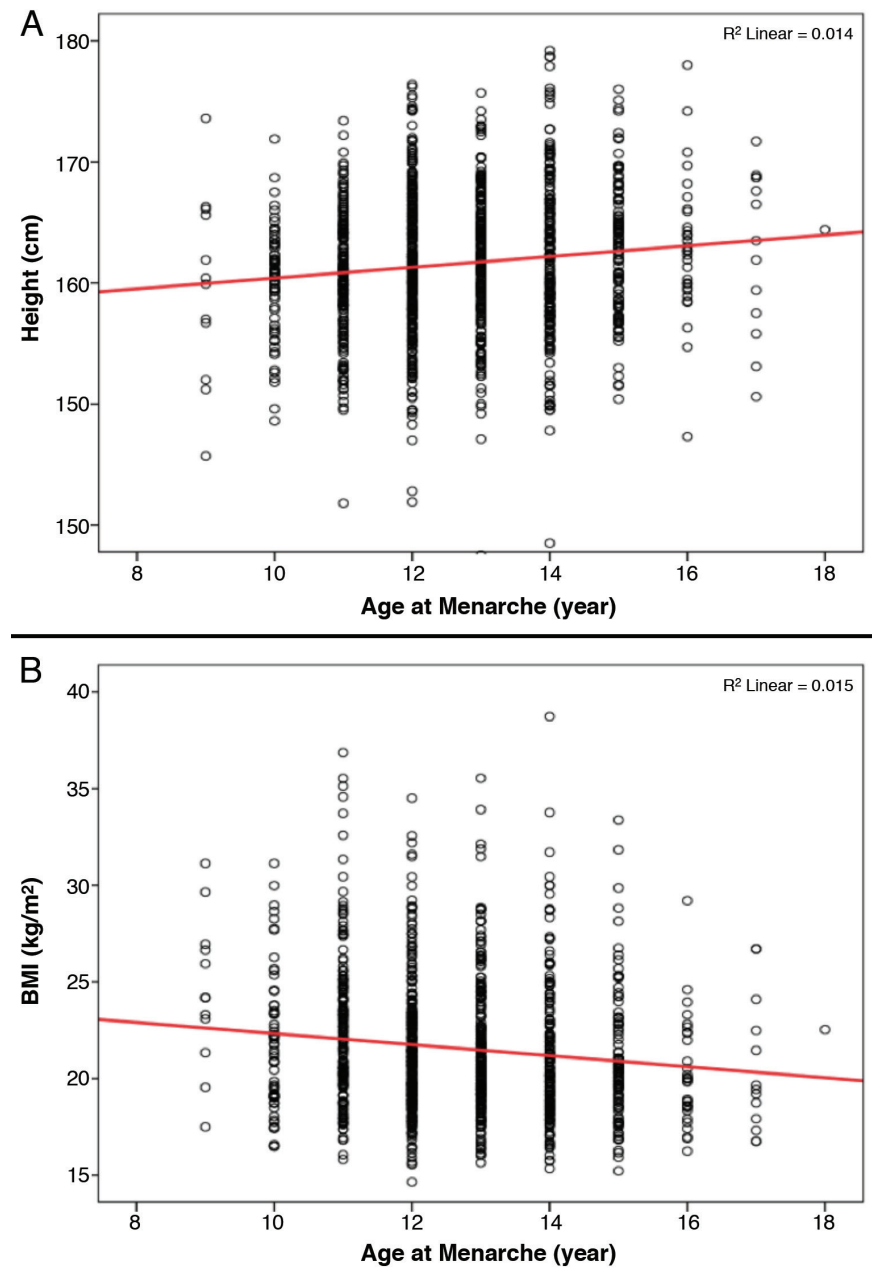

Figure 2. A, B) Height and body mass index according to age at menarche. Females were $0.445 \mathrm{~cm}$ shorter when menarche occurred 1 year earlier
The prevalence of early menarche has increased dramatically in Korea based on our study (5). In this study, the percentage of subjects who experienced menarche before the age of 12 years was $22.3 \%$, while this percentage in the mothers of the subjects was $2.5 \%$. The prevalence in the subjects was nine times higher than that of their mothers. Similar to many other countries, South Korea has shown rapid decrease of female age in menarche from mid-20th century to the present, and this is probably due to improvements in nutrition and living conditions $(13,20)$. In our previous study, we reported the rapid decrease of mean age of menarche over time, from $15.62 \pm 1.88$ years for females born between 1950 and 1954 , to $13.11 \pm 1.52$ years for those born between 1980 and 1984 , to $12.60 \pm 1.14$ years for those born between 1990 and 1994 (5). This trend might be due to changes in the socioeconomic environment, the most important of which is probably improvement in nutritional status (13). The nutritional status of South Korea rapidly improved after the Korean Civil War. South Koreans rapidly accepted western culture, especially in terms of dietary habits, after the 1988 Olympic Games, while North Korean refugees still show an age of menarche around $16.0 \pm 2.1$ years (20). Nutrition, in particular, appears to play an important role in the time of onset of menarche. There are great many reports indicating that girls with higher body weight, higher BMI and more body fat reach menarche at an earlier age $(13,21,22)$. It has been suggested that a 'critical weight' is needed for menarche to occur $(23,24)$. Furthermore, other factors such as birth weight, prenatal nutrition, type of diet and exposure to endocrine disruptors, have been suggested as likely contributory factors for earlier pubertal development and early menarche $(25,26,27)$. Another suggested reason for the increasing prevalence of early menarche in Korean girls is a rapid increase in the prevalence of central precocious puberty (CPP). CPP can cause early menarche in girls and result in short adult stature due to early epiphyseal fusion (11). The annual incidence of CPP in girls has significantly increased from 3.3 to 50.4 per 100,000 girls during 2004 to 2010 in Korea (28). The incidence of girls diagnosed with CPP has markedly increased in the 21 st century. In Denmark for instance, it is much higher compared to 40 years ago (29).

In this study, $10.5 \%$ of females with early menarche had a short stature. The OR for short stature was 2.62-fold after adjusting for current age and mother's height in females with early menarche compared to those with later menarche. In basic terms, for each year of delay in age at menarche, a Korean female will grow to be be approximately $0.445 \mathrm{~cm}$ taller in her final height. This finding agrees studies from other countries $(12,21,30,31)$. According to the European 
Prospective Investigation into Cancer and Nutrition study, based on 286,205 women from nine European countries, women grew approximately $0.35 \mathrm{~cm}$ taller when menarche occurred one year later (range by country: 0.13-0.50 cm) (12). Furthermore, a 1-year increase in age of menarche caused an increase in standing height, leg length and trunk height of $0.76,0.41$ and $0.35 \mathrm{~cm}$, respectively, in a USA birth cohort (31).

The pathogenesis of this trend in age of menarche may be explained by the earlier closure of epiphyseal growth plates due to an increase in ovarian estrogens $(32,33)$. A low dose of estrogen will induce stimulation of the growth hormoneinsulin-like growth factor 1 axis and a pubertal growth spurt in early puberty. However, increase in estrogen binding to its receptors in the growth plate cartilage might cause early epiphyseal fusion by advancing growth plate senescence (33). A delay in menarche allows continued growth of long bones before epiphyseal fusion, leading to an increase in adult height. Gonadotropin releasing hormone analog (GnRHa) treatment in girls with CPP could improve final adult height and increase the age of menarche close to that of the general population. The height gain achieved after GnRHa treatment in children with CPP, depends on the age of onset of puberty and onset of treatment (34).

In this study, the OR for obesity in females with early menarche was 1.73. However, after adjusting for age and maternal BMI, we failed to find an association between early menarche and obesity $(p=0.058)$. The most plausible reason for this might be the relatively small number of subjects analyzed. Additionally, socioeconomic factors assessed in our study failed to demonstrate an association with adult short height. This finding agrees with a previous Korean study and supports the hypothesis that socioeconomic status is not an independent predictor of age at menarche or final height in well-developed countries $(35,36)$.

\section{Study Limitations}

The major strength of the present study is that it is based on a national representative study population. However, this study has some limitations. First, the cross-sectional nature of the study prohibits making conclusions regarding the existence of a causal relationship between age of menarche and adult height. Second, we could not adjust for other confounders such as the fathers' height and birth weight, which might influence the subjects' adult height. Recent studies showed an association between lower birth weight and early menarche (26). Finally, the age at menarche was self-reported. It is known that age at menarche based on recall data is not very accurate, especially when the time between menarche and current age is more than three years
(37). However, other studies have shown high correlations ( $R=0.67$ to 0.79 ) between age at menarche by recall during middle-age and the original childhood data (38).

\section{Conclusion}

In conclusion, we found that early menarche is a risk factor for shorter adult stature and obesity in young Korean females. To the best of our knowledge, this is the first study to show that early menarche is a risk factor of short adult stature in Korean females. Some girls, despite being of normal height during childhood and during the pubertal years might grow to short adult stature due to earlier fusion of the growth plates. In light of the rapidly increasing prevalence of early menarche, knowledge concerning onset of puberty, progression tempo and age at menarche is important in identifying females at risk. Further long term cohort investigations are needed to fully explain these causal relationships.

\section{Ethics}

Ethics Committee Approval: The Research Ethics Committee of the Korea Centers for Disease Control approved the study protocol (no: 2013-07CON-03-4C, 2013-12EXP-03-5C).

Informed Consent: All participants or their parents signed a written informed consent form.

Peer-review: Externally and internally peer-reviewed.

\section{Authorship Contributions}

Concept: Jung Sub Lim, Design: Sol Kang, Jung Sub Lim, Data Collection or Processing: Yoon Mo Kim, Jun Ah Lee, Dong Ho Kim, Analysis or Interpretation: Sol Kang, Jung Sub Lim, Literature Search: Sol Kang, Jung Sub Lim, Writing: Sol Kang, Jung Sub Lim, Jun Ah Lee.

Financial Disclosure: No financial disclosure. This study was partially supported by a grant of the Korea Institute of Radiological and Medical Sciences (KIRAMS), funded by Ministry of Science and ICT (MSIT), Republic of Korea. (No. 50541-2018).

\section{References}

1. Dvornyk V, Waqar-ul-Haq. Genetics of age at menarche: a systematic review. Hum Reprod Update 2012;18:198-210. Epub 2012 Jan 18

2. Freedman DS, Khan LK, Serdula MK, Dietz WH, Srinivasan SR, Berenson GS. Relation of age at menarche to race, time period, and anthropometric dimensions: the Bogalusa Heart Study. Pediatrics 2002;110:43

3. Wronka I, Pawlińska-Chmara R. Menarcheal age and socioeconomic factors in Poland. Ann Hum Biol 2005;32:630-638 
4. Simondon KB, Simon I, Simondon F. Nutritional status and age at menarche of Senegalese adolescents. Ann Hum Biol 1997;24:521532.

5. Ahn JH, Lim SW, Song BS, Seo J, Lee JA, Kim DH, Lim JS. Age at menarche in the Korean female: secular trends and relationship to adulthood body mass index. Ann Pediatr Endocrinol Metab 2013;18:60-64. Epub 2013 Jun 30

6. Lim SW, Ahn JH, Lee JA, Kim DH, Seo JH, Lim JS. Early menarche is associated with metabolic syndrome and insulin resistance in premenopausal Korean women. Eur J Pediatr 2016;175:97-104. Epub 2015 Aug 9

7. Yi KH, Hwang JS, Lim SW, Lee JA, Kim DH, Lim JS. Early menarche is associated with non-alcoholic fatty liver disease in adulthood. Pediatr Int 2017;59:1270-1275

8. Lim JS, Lee HS, Kim EY, Yi KH, Hwang JS. Early menarche increases the risk of Type 2 diabetes in young and middle-aged Korean women. Diabet Med 2015;32:521-525. Epub 2014 Dec 30

9. Charalampopoulos D, McLoughlin A, Elks CE, Ong KK. Age at menarche and risks of all-cause and cardiovascular death: a systematic review and meta-analysis. Am J Epidemiol 2014;180:29-40. Epub 2014 Jun 11

10. Pedicelli S, Peschiaroli E, Violi E, Cianfarani S. Controversies in the definition and treatment of idiopathic short stature (ISS). J Clin Res Pediatr Endocrinol 2009;1:105-115. Epub 2009 Feb 1

11. Klein KO. Precocious puberty: who has it? Who should be treated? J Clin Endocrinol Metab 1999;84:411-414.

12. Onland-Moret NC, Peeters PH, van Gils CH, Clavel-Chapelon F, Key T, Tjønneland A, Trichopoulou A, Kaaks R, Manjer J, Panico S, Palli D, Tehard B, Stoikidou M, Bueno-De-Mesquita HB, Boeing H, Overvad K, Lenner P, Quirós JR, Chirlaque MD, Miller AB, Khaw KT, Riboli E. Age at menarche in relation to adult height: the EPIC study. Am J Epidemiol 2005; 162:623-632.

13. Hauspie RC, Vercauteren M, Susanne C. Secular changes in growth and maturation: an update. Acta Paediatr Suppl 1997;423:20-27.

14. Shangold MM, Kelly M, Berkeley AS, Freedman KS, Groshen S. Relationship between menarcheal age and adult height. South Med J 1989;82:443-445.

15. Ma HM, Du ML, Luo XP, Chen SK, Liu L, Chen RM, Zhu C, Xiong F, Li T, Wang W, Liu GL; Pubertal Study Group of the Society of Pediatric Endocrinology and Genetic Disease, Chinese Medical Association. Onset of breast and pubic hair development and menses in urban chinese girls. Pediatrics 2009;124:269-277. Epub 2009 Jul 27.

16. Al-Awadhi N, Al-Kandari N, Al-Hasan T, Almurjan D, Ali S, Al-Taiar A. Age at menarche and its relationship to body mass index among adolescent girls in Kuwait. BMC Public Health 2013;13:29.

17. Park HA. The Korea national health and nutrition examination survey as a primary data source. Korean J Fam Med 2013;34:79. Epub 2013 Mar 20

18. Kim JH, Yun S, Hwang SS, Shim JO, Chae HW, Lee YJ, Lee JH, Kim SC, Lim D, Yang SW, Oh K, Moon JS; Committee for the Development of Growth Standards for Korean Children and Adolescents; Committee for School Health and Public Health Statistics, the Korean Pediatric Society; Division of Health and Nutrition Survey, Korea Centers for Disease Control and Prevention. The 2017 Korean National Growth Charts for children and adolescents: development, improvement, and prospects. Korean J Pediatr 2018;61:135-149. Epub 2018 May 28

19. Yoon KH, Lee JH, Kim JW, Cho JH, Choi YH, Ko SH, Zimmet P, Son HY. Epidemic obesity and type 2 diabetes in Asia. Lancet 2006;368:16811688.
20. Cho GJ, Park HT, Shin JH, Hur JY, Kim YT, Kim SH, Lee KW, Kim T. Age at menarche in a Korean population: secular trends and influencing factors. Eur J Pediatr 2010;169:89-94. Epub 2009 Jun 7

21. Koprowski C, Ross RK, Mack WJ, Henderson BE, Bernstein L. Diet, body size and menarche in a multiethnic cohort. Br J Cancer 1999;79:19071911.

22. Atay Z, Turan S, Guran T, Furman A, Bereket A. Puberty and influencing factors in schoolgirls living in Istanbul: end of the secular trend? Pediatrics 2011;128:40-45. Epub 2011 Jun 13

23. Maclure M, Travis LB, Willett W, MacMahon B. A prospective cohort study of nutrient intake and age at menarche. Am J Clin Nutr 1991;54:649-656.

24. Stoll BA. Western diet, early puberty, and breast cancer risk. Breast Cancer Res Treat 1998;49:187-193.

25. Fisher MM, Eugster EA. What is in our environment that effects puberty? Reprod Toxicol 2014;44:7-14. Epub 2013 Apr 17

26. Sloboda DM, Hart R, Doherty DA, Pennell CE, Hickey M. Age at menarche: Influences of prenatal and postnatal growth. J Clin Endocrinol Metab 2007;92:46-50. Epub 2006 Oct 24

27. Carwile JL, Willett WC, Spiegelman D, Hertzmark E, Rich-Edwards J, Frazier AL, Michels KB. Sugar-sweetened beverage consumption and age at menarche in a prospective study of US girls. Hum Reprod 2015;30:675-683. Epub 2015 Jan 27

28. Kim SH, Huh K, Won S, Lee KW, Park MJ. A significant increase in the incidence of central precocious puberty among Korean girls from 2004 to 2010. PLoS One 2015;10:e0141844.

29. Teilmann G, Pedersen CB, Jensen TK, Skakkebaek NE, Juul A. Prevalence and incidence of precocious pubertal development in Denmark: an epidemiologic study based on national registries. Pediatrics 2005; 116:1323-1328.

30. Georgiadis E, Mantzoros CS, Evagelopoulou C, Spentzos D. Adult height and menarcheal age of young women in Greece. Ann Hum Biol 1997;24:55-59.

31. Osuch JR, Karmaus W, Hoekman P, Mudd L, Zhang J, Haan P, Mikucki D. Association of age at menarche with adult leg length and trunk height: Speculations in relation to breast cancer risk. Ann Hum Biol 2010;37:76-85.

32. Emons J, Chagin AS, Sävendahl L, Karperien M, Wit JM. Mechanisms of growth plate maturation and epiphyseal fusion. Horm Res Paediatr 2011;75:383-391. Epub 2011 May 4

33. Börjesson AE, Lagerquist MK, Windahl SH, Ohlsson C. The role of estrogen receptor $\alpha$ in the regulation of bone and growth plate cartilage. Cell Mol Life Sci 2013;70:4023-4037. Epub 2013 Mar 21

34. Bereket A. A Critical Appraisal of the Effect of Gonadotropin-Releasing Hormon Analog Treatment on Adult Height of Girls with Central Precocious Puberty. J Clin Res Pediatr Endocrinol 2017;9(Suppl 2):33-48.

35. Lee MH, Kim SH, Oh M, Lee KW, Park MJ. Age at menarche in Korean adolescents: trends and influencing factors. Reprod Health 2016;13:121.

36. Talma H, Schönbeck Y, van Dommelen P, Bakker B, van Buuren S, Hirasing RA. Trends in menarcheal age between 1955 and 2009 in the Netherlands. PLoS One 2013;8:e60056.

37. Castilho SD, Nucci LB, Assuino SR, Hansen LO. [The importance of memory bias in obtaining age of menarche by recall method in Brazilian adolescents]. Arq Bras Endocrinol Metabol 2014;58:394-397.

38. Must A, Phillips SM, Naumova EN, Blum M, Harris S, Dawson-Hughes $B$, Rand WM. Recall of early menstrual history and menarcheal body size: after 30 years, how well do women remember? Am J Epidemiol 2002;155:672-679 